\title{
Daniel Machado'
} Taiza Mara Rauen Moraes ${ }^{2}$

\section{Fotografia rizomática: $u m a$ proposta para cartografia de memorias}

Rhizomatic photography: a proposal for memory cartography

Photographie rhizomatique: une proposition de cartographie mémoire 


\title{
Resumo
}

Propomos no artigo o alinhamento do conceito de rizoma de Deleuze $\&$ Guattari à fotografia, compreendendo-a como um artefato cultural possível para estudos culturais. A fotografia rizomática é apresentada como articuladora da história, da cultura e da memória.

Palavras-chave: Rizoma. Fotografia. Estudos culturais. Memória.

\begin{abstract}
We propose in the article the alignment of rhizome concept of Deleuze $\&$ Guattari's to photography, understanding it as a possible cultural artifact for cultural studies. Rhizomatic photography is presented as an articulator of history, culture and memory.
\end{abstract}

Key-words: Rhizome. Photography. Cultural studies. Memory.

\section{Résumé}

Nous proposons dans l'article l'alignement du concept de rhizome de Deleuze \& Guattari sur la photographie, en le comprenant comme un possible artefact culturel pour les études culturelles. La photographie rhizomatique est présentée comme un articulateur de l'histoire, de la culture et de la mémoire.

Mot-clés: Rhizome. Photographie. Études culturelles. Mémoire.

\footnotetext{
${ }^{1}$ Fotógrafo e pesquisador. Mestre em Patrimônio Cultural e Sociedade pela UNIVILLE. Docente nos cursos superiores de Fotografia e Publicidade e Propaganda da UNIVILLE. Link para lattes: http://lattes.cnpq.br/7460430091613884. ORCID: https://orcid.org/0000-0002-3624-5339. E-mail: contato@fotografodaniel.com

${ }^{2}$ Doutora em Literatura pela Universidade Federal de Santa Catarina. Professora da graduação, mestrado e doutorado em Patrimônio Cultural e Sociedade da UNIVILLE. Coordenadora do PROLER UNIVILLE. Link para lattes: http:Il lattes.cnpq.br/5574002164226642. ORCID: https://orcid.org/0000-0002-6389-1133. E-mail: moraes.taiza@gmail.com
} 


\section{Introdução}

O artigo visa demonstrar que o conceito de rizoma proposto por Deleuze \& Guattari, é passível de propiciar novas perspectivas de percepção da fotografia imbricando-a com a metodologia da história oral para cerzir identificações através das memórias manifestadas em decorrência das imagens, como "formas muito diversas, desde sua extensão superficial ramificada em todos os sentidos até suas concreções em bulbos e tubérculos" (DELEUZE; GUATTARI, 2011, p. 22), ou seja, a partir de sua superfície ramificada pelos múltiplos elementos que compõe a fotografia, a paisagem, os personagens, vestimentas, objetos, e até mesmo os suportes, o papel; evocam lembranças que se expandem em múltiplos sentidos até a concreção em narrativas.

Compreendemos a fotografia rizomática como um artefato cultural apresentado em coleções específicas, elaboradas por seus proprietários - fotografias de viagens, da casa, dos filhos -, que possibilita e promove múltiplas conexões desencadeadas pelo conteúdo imagético visível e pelo conjunto das narrativas coletadas, conteúdos orais heterogêneos conectáveis em diversos pontos na mesma narrativa e coleção fotográfica, bem como com outras narrativas e coleções fotográficas apreciadas no mesmo contexto. Em decorrência na fotografia rizomática "cadeias semióticas de toda natureza são aí conectadas a modos de codificação muito diversos, cadeias biológicas, políticas, econômicas, etc." (DELEUZE; GUATTARI, 2011, p. 22), abrindo-se a diversos sistemas de comunicação utilizados pelos grupos que apresentam suas coleções.

A natureza rizomática da fotografia conduz as memórias e consequentes narrativas por caminhos imprevistos, resultados das relações e vivências de cada observador, as quais, como afirma Aleida Assmann, não devemos entender como ficção ou mentira aquilo que não é aderente à "verdade histórica", mas como "recordações formuladas a partir de padrões interpretativos adquiridos nesse meio-tempo, [o tempo do fato ocorrido e o tempo da recordação] [...] uma contribuição importante para a estabilização das recordações no desenvolvimento de uma identidade pessoal" (ASSMANN, 2011, p. 275). Uma fotografia, ou um conjunto de fotografias apreciado por pessoas diversas, resultará em memórias diferentes, assim como, a mesma fotografia ou conjunto, apreciado pelo mesmo observador em momentos diferentes, resultará em memórias diferentes. No conceito de Deleuze \& Guattari (2011, p. 25), são estas multiplicidades as linhas de fuga - aqui, as memórias - que "mudam de natureza ao se conectarem às outras".

\section{Fotografia como rizoma}

Prosseguindo a discussão de conceito de fotografia rizomática, abordaremos o princípio de "ruptura assignificante" proposto por Deleuze \& Guattari (2011, p. 25), no qual "um rizoma pode ser rompido, quebrado em um lugar qualquer, e também retoma segundo uma ou outra de suas linhas e segundo outras linhas". Na observação de um conjunto de fotografias é comum o observador romper sua observação 
sobre um tema específico e ser atraído por outros temas a partir de outras fotografias, logo, se constata que o tema anterior volta à tona trazido por novas fotografias, produzindo um movimento de rupturas e conexões inesperadas.

Percebemos na observação de conjuntos fotográficos apresentados por quem com eles possui relações, que o princípio de cartografia se faz presente no movimento de observação e apresentação. Não há um roteiro determinado neste movimento e por mais que se busque seguir um caminho, facilmente o narrador é levado para outros rumos, motivado por uma fotografia ou memória inesperada demarcadores de novos trajetos. Bem como, assimilamos o princípio de cartografia à fotografia rizomática, a qual não se compõe por meio de um modelo estrutural rígido, pois a elaboração cartográfica e as narrativas decorrentes estão "inteiramente voltadas para uma experimentação ancorada no real" (DELEUZE; GUATTARI, 2011, p. 30).

A heterogeneidade da fotografia considerada um rizoma promove conexões com quem a lê e faz brotar múltiplos saberes. A cada momento da vida em que a fotografia é lida suscita novas leituras porque a memória é associada ao presente vivido. Neste sentido, a fotografia é viva quando plantada em terreno fértil e cresce entre os seus, desvelando aspectos de seus criadores, das pessoas próximas a eles ou próximas ao contexto apresentado, por quem possui com elas maior dialogismo. Portanto, a fotografia identificada como rizoma é investigada como uma linha que se conecta em múltiplos pontos e não como a árvore que se fixa em único lugar, pois a cada leitura ela pode conduzir o olhar a diferentes lugares e criar novas conexões.

Deleuze \& Guattari (2011, p. 25) ao articularem o princípio de multiplicidade no conceito de rizoma, advertem que "o ideal de um livro seria expor toda coisa sobre tal plano de exterioridade, sobre uma única página, sobre uma mesma paragem: acontecimentos vividos, determinações históricas, conceitos pensados, indivíduos, grupos e formações sociais". Podemos ver na fotografia esta paragem, esta página em que todos os elementos citados pelos autores são expostos através da narrativa de memória de quem com ela possui relações. Quanto maior o dialogismo com o artefato, maior o "tal plano de exterioridade" da fotografia. Assim, a fotografia também pode ser compreendida como o rizoma, a-significante, pois os saberes, pensamentos, narrativas desenvolvidas a partir de seu conteúdo, quando rompidos podem retomar outro ponto de contato a partir da mesma fotografia ou mesmo de fotografias análogas. A leitura da fotografia, portanto pode viabilizar ou não apenas a retomada de pontos de contato, visto que o rompimento pode também causar a fuga. Bem como pode ser uma fagulha responsável por disparar uma explosão de pensamentos, memórias, linhas que não necessariamente precisam retornar a ela para ter continuidade.

Linhas se espalham pelo campo pesquisado permitindo a leitura por atalhos ou caminhos não previstos. Esse movimento da leitura da narrativa a partir de uma fotografia decorrente da adoção do princípio da cartografia proposto por Deleuze \& Guattari (2011), parte da negação de modelos estruturais ou gerativos. Em decorrência, a construção é efetuada no caminhar, no conhecer os pontos que surgem no encontro das linhas narrativas e de conceitos. Portanto, a pesquisa cultural baseada em narrativas de memórias provocadas por fotografias é aberta, "conectável em todas as suas dimensões, desmontável, reversível, suscetível de receber modificações cons- 
tantemente" (DELEUZE; GUATTARI, 2011, p. 30). A forma rizomática permite múltiplas entradas de leitura e em qualquer ponto, pois num mapa a leitura pode ser desenvolvida a partir da escolha entre os inúmeros caminhos possíveis sem um roteiro prévio a ser seguido, o leitor é quem estabelece as rotas de seu trajeto. Portanto, devido ao caráter aberto do rizoma, a pesquisa não pode ser fechada, "arborificada"1, porque ela se encontra no entre lugar, das memórias, das narrativas, e como afirma Deleuze \& Guattari (2011, p. 32), "seria necessário sempre ressituar os impasses sobre o mapa e por aí abri-los sobre linhas de fuga possíveis". Em decorrência, os resultados da pesquisa orientada no movimento da fotografia rizomática não são passíveis de serem lidos como unidades que possuem começo e fim, porque são um meio, "um mapa que deve ser produzido, construído, sempre desmontável, conectável, reversível, modificável, com múltiplas entradas e saídas, com suas linhas de fuga" (DELEUZE; GUATTARI, 2011, p. 43).

Assim sendo, nesta ótica a pesquisa é concebida como um conjunto de platôs ${ }^{2}$ por estar no meio, tendo o meio não como uma média, como afirma Deleuze $\&$ Guattari (2011), como um lugar de exponenciação das coisas, no entorno da história e das memórias. Nela não há capítulos possíveis com pontos de conclusão, mas platôs que se comunicam e complementam-se entre si, interligados por uma raiz "subterrânea" conectável em múltiplos pontos, possíveis de extensão e de variados caminhos de leitura, possibilitando ao leitor posicionar e relacionar as narrativas a seu próprio modo.

A fotografia compreendida como rizoma, é focada como um artefato cultural capaz de abrir brechas históricas no conhecimento de costumes, ritos, expressões e práticas diversas, capacidade que vem da potencialidade em suscitar memórias as quais, na conexão com a história oral, constroem narrativas e constituem narradores. Benjamin (1994), ao refletir sobre a narrativa evidencia que "a experiência que passa de pessoa a pessoa é a fonte a que recorrem todos os narradores", assim , ao descrever uma fotografia, quem a apresenta nem sempre viveu o que está nela representado, mas aciona memórias que lhe foram transmitidas.

\section{História oral e as narrativas a partir de fotografias de família}

A conexão entre cartografia e História Oral possibilita abordagens francas às fontes orais, de onde emanam as narrativas que dão vida e conteúdo à investigação. Podemos afirmar que a abordagem é franca, porque o papel do entrevistador não é criticar ou buscar modificar crenças, opiniões e visões do colaborador (ALBERTI, 2013), nem persuadi-lo a seguir este ou aquele caminho. As memórias emersas a partir das fotografias apresentadas pelo colaborador são resultantes de sua experiência de vida, e não convém o julgamento em uma pesquisa que busca conhecer aspectos culturais.

\footnotetext{
1 "Quando um rizoma é fechado, arborificado, acabou, do desejo nada mais passa; porque é sempre por rizoma que o desejo se move e produz" (DELEUZE; GUATTARI, 2011, p. 32). Deleuze utiliza o termo arborificado para contrapor a proposta de rizoma. Enquanto o rizoma conceitua o pensamento horizontal, ramificado, com muitas vertentes e conexões, o pensamento arborificado se fecha num único eixo estrutural ou gerativo, constituído de hierarquias.

2 "Gregory Bateson serve-se da palavra "platô" para designar algo muito especial: uma região contínua de intensidades, vibrando sobre ela mesma, e que se desenvolve evitando toda orientação sobre um ponto culminante ou em direção a uma finalidade exterior. " (DELEUZE; GUATTARI, 2011, p. 44)
} 
Apoiados em Benjamin, podemos considerar os colaboradores das entrevistas a partir da fotografia rizomática como narradores que "retira[m] da experiência o que ele[s] conta[m]: sua[s] própria[s] experiência[s] ou a relatada pelos outros. E incorpo$\mathrm{ra}[\mathrm{m}]$ as coisas narradas à experiência dos seus ouvintes" (BENJAMIN, 1994, p. 201). Vale ressaltar que, na história oral, as narrativas decorrentes da fotografia rizomática não visam se opor "ao domínio escriturístico moderno" (GUIMARÃES NETO, 2012, p. 16-17), e sim, possibilitar um olhar sobre outro ponto de vista, "de baixo", do meio do povo, como no exemplo da narrativa de Máuri citada por Portelli em "A filosofia e os fatos" (1996), como uma alternativa às narrativas impostas e geralmente institucionalizadas que são construídas "do alto", por quem muitas vezes não teve contato com o povo, mas apenas com documentos oficiais. Mais do que uma documentação cartesiana do passado, a proposta da metodologia é dar espaço as vivências, as individualidades, buscando conhecer o todo de uma cultura, de um local, através da experiência individual, abordando o passado na relação entre entrevistador e colaborador, nessa filosofia da memória, na qual "recordar e contar já é interpretar" (PORTELLI, 1996).

A fotografia rizomática suscita narrativas culturais que podem ir além da reprodução do visível, pautada em tornar visível "os sem-imagem, excluídos tanto da visibilidade dominante como da vida social e política: os estrangeiros em seu próprio país [fotografando não] 'as' coisas ou 'as' pessoas, mas os estados de coisas e com as pessoas" (ROUILLÉ, 2009, p. 184).

O intenso dialogismo presente na fotografia de família permite o acesso acentuado a vivências dos grupos familiares e das consequentes situações retratadas, por estar o operador da câmera aqui, compartilhando rotineiramente sua vida com o outro. A força expressiva das fotografias de família está menos em sua estética e mais na "imanência de seu dialogismo" (ROUILLÉ, 2009, p. 186), que trás consigo características profundas do campo cultural em seu entorno, aprofundadas também pelo fato do "leque temático" destas fotografias ser bastante restrito, "dominado por um número limitado de lugares, objetos, indivíduos e de situações que as imagens conjugam infinitamente" (ROUILLÉ, 2009, p. 186).

Em decorrência, a observação das fotografias de família, apresentadas por seus proprietários imbricadas aos relatos e memórias associadas aos conjuntos fotográficos apresentados, (re) signifacam-na em artefato cultural repleto de expressão, munido de um conteúdo sobre o universo cultural em que a família está inserida. Artefato cultural que apresenta situações específicas de determinada família, comunidade, grupo social, retratando objetos familiares, carros, casas, brinquedos, temas cotidianos, festas familiares, cenas de lazer, onde vez ou outra, está representado o patrimônio cultural imaterial, como define a UNESCO (2003) com “práticas, representações, expressões, conhecimentos e técnicas - junto com os instrumentos, objetos, artefatos e lugares culturais que lhes são associados", manifestados nas "práticas sociais, rituais e atos festivos, nos conhecimentos e práticas relacionados à natureza e ao universo" em que a família está inserida. Assim, apesar de na fotografia de família encontrarmos frequentemente capturas fugidias de momentos cotidianos, capturas de objetos, veículos, imóveis, são as fotografias de eventos como casamento, pri- 
meira comunhão, aniversário, retratos produzidos por algum ente próximo ou por fotógrafos profissionais que ocupam normalmente as paredes das casas ou porta-retratos distribuídos pelos móveis.

As fotografias familiares, representam valores de memória para a família e por convenção popular ocupam comumente os álbuns ou caixas de fotografias, suportes que, como afirma Rouillé (2009, p. 186) são "ponto de encontro dos indivíduos com sua própria imagem e com a de seus próximos", e que, cada vez que abertos são como imposição externa que insinua fragmentos da memória, mutável em "harmonia instável, bricolada", como afirma Certeau (2009). Olhar para as fotografias de família como artefatos culturais evoca o caráter cultural deste material definido muitas vezes como simples ferramenta útil, e as posiciona juntamente com o movimento recente da fotografia, que segundo Rouillé (2009), tem se voltado para o campo das pesquisas, das teorias e dos textos a partir da década de 1970, quando também iniciou seu reconhecimento cultural. Estes artefatos culturais abrem janelas em nossa memória e fazem emergir relatos sobre o que vivenciamos ou o que ouvimos de quem vivenciou, guardou e apresentou determinada fotografia. Janelas possíveis em qualquer área da fotografia, mas que na fotografia de família é impulsionada pelo dialogismo presente no circuito fotógrafo - modelo - receptor - herdeiro.

O movimento da leitura da narrativa a partir de uma fotografia decorrente da adoção do princípio da cartografia proposto por Deleuze \& Guattari (2011), parte da negação de modelos estruturais ou gerativos, assim a construção é efetuada no caminhar, no conhecer os pontos que surgem no encontro das linhas narrativas e de conceitos.

A pesquisa, nesta ótica é concebida como um conjunto de platôs por estar no meio, tendo o meio não como uma média, como afirma Deleuze \& Guattari (2011), mas como um lugar de exponenciação das coisas, no entorno da história e das memórias. Nela não há capítulos possíveis com pontos de conclusão, mas platôs que se comunicam e complementam-se entre si, interligados por uma raiz "subterrânea" conectável em múltiplos pontos, possíveis de extensão e de variados caminhos de leitura.

\section{Fotografia e memória}

A fotografia é um "símbolo externo" responsável pela preservação de nossa memória, "um objeto que faz lembrar" no contato com a "mente que lembra" resultando na metonímia conhecida por memória (ASSMANN, v. 19, 2016). Ela é um artefato da memória cultural na qual heranças identitárias são preservadas e transmitidas através das narrativas de memória suscitadas por sua observação, se tornando um significativo suporte da identidade coletiva e individual, importante para o reconhecimento do indivíduo ou do grupo, no espaço em que ele se encontra e fora dele.

As memórias afloradas pela fotografia foram inscritas em quem as observou em ocasiões como o momento da captura, quando a fotografia lhe foi apresentada juntamente com os relatos de quem vivenciou a captura, ou ainda pode não possuir 
relação nenhuma com a fotografia em questão, mas com o que está nela apresentado, sendo a fotografia, no pensamento de Certeau (2009), uma circunstância para a lembrança dessas "escrituras invisíveis".

Quando a memória é revelada a partir de uma fotografia, é comum vermos o narrador integrando o fotografado aos outros pontos de sua história, seja quando ele vivenciou o que está representado na fotografia ou não. Desta forma, a narrativa decorrente de uma fotografia, quando reproduzida, nunca será idêntica mesmo que reproduzida pelo mesmo narrador, porque ele trará a cada reprodução vivências diferentes assimiladas à fotografia. Esta distinção tende a ser ampliada quando a fotografia é apresentada por outra pessoa, alargando as percepções de olhares.

Cada memória acionada a partir de uma fotografia é revelada à sua própria luz, pois a memória "não possui uma organização já pronta de antemão que ela apenas encaixaria ali. Ela se mobiliza relativamente ao que acontece - uma surpresa, que ela está habilitada a transformar em ocasião. Ela só se instala num encontro fortuito, no outro" (CERTEAU, 2009, p. 150), e aqui podemos considerar o "outro" como a pessoa a quem a fotografia é apresentada, mas também como o próprio artefato fotográfico que mesmo sem ser apresentado à alguém, provoca um "encontro fortuito" entre memória, fatos presentes e a imagem capturada.

O narrador, segundo Benjamin (1994), e aqui podemos incluir aqueles que tomam como base para seus relatos as fotografias, o fazem de maneira artesanal, com muita naturalidade, utilizando sua própria forma de linguagem, sem amarras técnicas e estruturais, relatando suas memórias ao seu próprio modo, muitas vezes revelando fatos difusos, criando os elos que the são pertinentes, avançando e retornando no tempo, caminhando pelo espaço físico e das fotografias da maneira que lhes convém, buscando propositalmente construir uma narrativa envolvente para conduzir o ouvinte, mas também em certos momentos sendo eles mesmos conduzidos pelo tempo de emersão de suas memórias. Não há ponto final quando conversamos com e a partir de uma fotografia, pois as indagações possíveis são inúmeras e as memórias suscitadas tendem a evocar outras séries de imagens, físicas ou mentais.

O senso prático característico dos narradores, como citado por Benjamin (1994), também é algo muito presente nas narrativas conduzidas a partir de fotografias. É muito comum que entre um relato e outros, surjam conselhos, dicas práticas de vivência e pequenos ensinamentos científicos como a forma de assar um pão "corretamente" ou o melhor período para plantar determinado legume. $O$ narrador nato almeja a precisão, por isso não se importa de complementar sua narrativa sobre a fotografia que ilustra um campo coberto pela geada com ensinamentos de como prever os prejuízos decorrentes de uma geada, ou a partir do retrato de uma tia, lembrar de uma "torta" que ela fazia e replicar a receita para o ouvinte.

O fim do narrador fotográfico com base em Benjamin é previsível em decorrência da cultura virtual, na qual estamos inseridos e pelo consequente descarte veloz de informações, incluem-se aqui as fotografias, principalmente as digitais. Com o descarte acontecendo "nessa dinâmica de velocidade incontida, desenfreada, perdem-se as referências, diluem-se os substratos da vida, reduzem-se as possibilidades de construção do saber" (DELGADO, 2003, v. 6, p. 22). Assim sendo, aquele narrador 
que observa uma fotografia de forma apreciativa, deixando fluir as memórias, emoções, análises, reflexões, tende a desaparecer com os intuídos hábitos de visualização digital, onde a velocidade do dedo é mais rápida que o tempo do olhar.

\section{Fotografias de família à luz de Didi-Huberman}

Didi-Huberman $(2012$, v. 2, p. 213) ao refletir sobre as imagens atenta que elas não estão "no presente", e por isso "são capazes de tornar visíveis as relações de tempo mais complexas que incumbem a memória na história". Benjamin comparou a narrativa às "sementes de trigo que durante milhares de anos ficaram fechadas hermeticamente nas câmaras das pirâmides e que conservam até hoje suas forças germinativas" (BENJAMIN, 1994, p. 204), podemos aqui fazer uma analogia com as fotografias, que quando armazenadas não em câmaras, mas das câmeras para outros suportes como as caixas de sapato, álbuns, porta retratos, cada vez que revisitadas têm sempre a "força germinativa" de suscitar memórias e narrativas.

Estas sementes fotográficas convenientes para a produção de rizomas em forma de narrativas históricas e culturais, são aditivos para o motor historiográfico, possuem a capacidade de abrir brechas na história, pois suas linhas visuais desdobram-se em linhas verbais a partir da narrativa de seu observador, que por sua vez podem ser valorados em uma pesquisa cartográfica.

A fotografia nunca esteve tão em evidência, nunca se fotografou tanto e se publicou tantas fotografias, mas com esse excesso de informação imagética, há também uma crítica em alta, nunca se observou tão pouco. Seguindo o pensamento de Didi-Huberman (v. 2, 2012), esse excesso de fotografias publicadas ultimamente, em sua grande maioria não são verdadeiras, pois são tão efêmeras que não chegam a tocar o real. O contrário acontece com fotografias de acervos familiares, guardadas às vezes por mais de uma geração ou fotografias recentes, até mesmo digitais, mas que possuem uma relação com quem as apresentam, fotografias que foram capturadas com propósito de guarda, conservação de um determinando momento ou objeto, e não apenas como um ato quase instintivo de clicar-publicar.

Os saberes revelados com a pesquisa que tem como base a fotografia rizomática para conhecimento de uma cultura, dispõe-se a auxiliar na resposta da questão levantada por Didi-Huberman (2012, v. 2, p. 209), em seu texto “Quando as imagens tocam o real": "Que tipo de contribuição ao conhecimento histórico é capaz de aportar este "conhecimento pela imagem?". Aqui, a contribuição ao conhecimento histórico está nas narrativas trazidas à tona a partir das fotografias de quem está inserido na história, na cultura do tema pesquisado, sendo a fotografia um reforço para "a posterioridade da memória, o hiato que se verifica entre a experiência e sua repetição na recordação" (ASSMANN, 2011, p. 179).

Essa contribuição permite uma cartografia de memórias cuja montagem inicial é produzida de dentro para fora, sendo os agentes inseridos no tema pesquisado os primeiros a darem as cartas, no caso, as fotografias, uma vez que são eles quem selecionam o que é apresentado ao pesquisador que pode iniciar a abordagem da 
pesquisa solicitando fotografias que de alguma forma possuam relação com o tema pesquisado. A partir daí o colaborador apresenta o que julga pertinente ao tema e muitas vezes, ao navegar entre uma foto e outra, é comum apresentar fotografias que para ele são importantes, são marcos em sua vida pessoal, o que pode vir acompanhado de uma memória que se distancia do foco da pesquisa.

Tal contribuição abre brechas em uma história habitualmente elaborada de forma hegemônica, pois os saberes de pessoas não celebrizadas são comumente deixados de lado. Brechas que facilmente podem permanecer fechadas permanentemente, uma vez que o conhecimento, os saberes, as memórias daqueles responsáveis por suas aberturas apagam-se com o tempo, com a morte. É comum que até as fotografias percam seu valor afetivo quando a memória relacionada a elas é perdida. Quando isso acontece, os saberes possíveis acerca destas fotografias tornam-se limitados ao visível na imagem, tornando latente aquilo que somente a memória e as relações podem manifestar.

\section{Considerações finais}

O conhecimento pela imagem, especificamente aqui, pelas fotografias pessoais de quem está inserido na história, e que afloram memórias que geram narrativas pessoais, produz uma contribuição ao conhecimento histórico do tema pesquisado que não possuem precedentes e dificilmente poderá ser reproduzido de forma idêntica, considerando principalmente o fato de que as memórias são mutáveis e também, que o conjunto de fotografias selecionadas de forma pessoal tende a ser alterado no percurso da vida do colaborador. Temos um "conhecimento dotado de um índex de identidade" (ASSMANN, 2016, v. 19, p. 126) pois emerge da memória de indivíduos.

O material com o qual estamos tratando nesta pesquisa não é do presente, a fotografia é responsável por desencadear memórias, observadas aqui na dimensão dos estudos culturais, considerando portanto, como sugere Assmann (2011, p. 23), os "meios culturais e técnicos da memória", que no tempo presente são emersões do passado, provocando um olhar através do tempo que trás em si a marca da historicidade, memórias que segundo Assmann (2016, v. 19, p. 116), são "a faculdade que nos capacita a formar uma consciência da identidade". Delgado (v. 6, 2003) afirma que o tempo não pode modificar o que passou, no entanto, ele "atua modificando ou reafirmando o significado do passado", pois há "um deslocamento fundamental entre o que foi arquivado e sua recuperação" (ASSMANN, 2011, p. 33). Isso é evidente ao analisar o conjunto de narrativas de uma cultura na qual as memórias sobre um mesmo fato são trazidas à tona por mais de uma pessoa, porém com intensidades e significados diferentes.

Desta forma, é impossível recompor os fatos do passado de forma integral, este seria um objetivo audacioso e incoerente afinal, "a memória não deve ser compreendida como um recipiente protetor, mas como uma força imanente, como uma energia com leis próprias" (ASSMANN, 2011, p. 34). Além do mais, não visamos entender o passado, mas revelá-lo, utilizando da síntese entre tempo e identidade provocada 
pela memória (ASSMANN, v. 19, 2016) que deve ser apreciada como um caminho da temporalidade da vida do colaborador, sujeito a acidentes, embates, pontes e buracos. O mesmo podemos afirmar em relação ao lugar, uma vez que "a memória mediatiza transformações espaciais" (CERTEAU, 2009, p. 149), e nela é possivel a transgressão da "lei do lugar" pensada por Certeau na qual

\begin{abstract}
um lugar é a ordem (seja qual for) segundo a qual se distribuem elementos nas relações de coexistência. Aí se acha, portanto, excluída a possibilidade, para duas coisas, de ocuparem o mesmo lugar. Aí impera a lei do 'próprio': os elementos considerados se acham uns ao lado dos outros, cada um situado num lugar 'próprio' e distinto que define. Um lugar é, portanto, uma configuração instantânea de posições. Implica uma indicação de estabilidade. (CERTEAU, 2009, p. 184)
\end{abstract}

Através da memória, portanto, a indicação de estabilidade é substituída pela instabilidade do lugar que nem sempre possui uma posição definida, pode-se deslocar no vacilo da memória ocasionando inclusive na possibilidade de duas coisas ocuparem o mesmo lugar. No movimento de observação da fotografia rizomática é perceptível como a memória é construída e organizada no processo, frequentemente a partir de vinculações com outras mídias expostas no movimento assim como, com fatos vivenciados em momentos distintos daqueles apresentados nas fotografias. $\dot{E}$ perceptível também, como a memória transpõe gerações a partir da fotografia quando um narrador apresenta relatos de um momento que não foi por ele vivenciado, mas que dele possui memórias pois alguém da geração passada, pais, avós, tios, lhe apresentaram a fotografia com o que dela possuíam de memórias, ou ainda quando hoje, a fotografia é apresentada para novas gerações, transmitindo ou retransmitindo relatos de memória a partir dela. Movimento que no processo de digitalização das fotografias vem sendo reduzido, ou ao menos modificado, pois a prática de imprimir fotografias foi consideravelmente reduzida nos últimos anos e com isto, a observação coletiva presencial de fotografias de família se tornou um hábito menos frequente.

Cerzir a história a partir das narrativas de memória de uma população é possibilitar a preservação de "seus elos, sua base identitária e a substância de sua história", fatores que se "perdem na dinâmica incessante do tempo" (DELGADO, v. 6, 2003, p. 14). Perdem-se com a morte que leva consigo a memória do narrador, apagam-se com a perda dos referentes responsáveis por fazer emergir determinadas memórias, como no caso da fotografia que se extravia. Isso sem falar das histórias hegemônicas que se impõe a determinadas culturas e acabam por sobrepor as memórias nativas. Conforme proposto por Certeau (2009), as narrativas populares são imbricadas ao discurso científico como "modelo", e não apenas como "objetos textuais a tratar". Compreendemos em consonância com o pensador francês, que as memórias expostas pelos habitantes através da narrativa são "um 'saber-dizer' exatamente ajustado a seu objeto e, a este título, não mais o outro do saber mas uma variante do discurso que sabe e uma autoridade em matéria de teoria" (CERTEAU, 2009, p. 141). 


\section{Referências}

ALBERTI, V. Manual de História Oral. 3. ed. Rio de Janeiro: FGV, 2013.

ASSMANN, A. Espaços da recordação: formas e transformações da memória cultural. Campinas: Unicamp, 2011.

ASSMANN, J. Memória comunicativa e memória cultural. História Oral, v. 19, n. 1, p. 115-128-128, 8 ago. 2016.

BENJAMIN, W. O Narrador: Considerações sobre a obra de Nikolai Leskov. In: Magia e técnica, arte e política: ensaios sobre literatura e história da cultura. 7. ed. São Paulo: Brasiliense, 1994. p. 198-221.

CERTEAU, M. de. A invenção do cotidiano. 16. ed. Petrópolis: Vozes, 2009.

DELEUZE, G.; GUATTARI, F. Mil platôs: capitalismo e esquizofrenia. 2. ed. São Paulo: Editora 34, 2011. v. 1

DELGADO, L. de A. N. História oral e narrativa: tempo, memória e identidades. História Oral, v. 6, p. 9-25, 2003.

DIDI-HUBERMAN, G. Quando as imagens tocam o real. Pós, v. 2, p. 204-219, 2012.

GUIMARÃES NETO, R. B. Historiografia, diversidade e história oral: questões metodológicas. História Oral, desigualdades e diferenças, v. 1, n. 1, p. 333, 2012.

ORGANIZAÇÃO DAS NAÇÕES UNIDAS PARA A EDUCAÇÃO, CIÊNCIA, E A CULTURA (UNESCO). Convenção para a salvaguarda do patrimônio cultural imaterial, 2003.

PORTELLI, A. A Filosofia e os Fatos. T e m p o, v. 1, p. 9, 1996.

ROUILLÉ, A. A fotografia entre documento e arte contemporânea. São Paulo: Senac, 2009. 